\title{
Prey-Capture Strategies of Fish-Hunting Cone Snails: Behavior, Neurobiology and Evolution
}

\author{
Baldomero M. Olivera ${ }^{a}$ Jon Seger ${ }^{a}$ Martin P. Horvath ${ }^{a}$ Alexander E. Fedosov ${ }^{b}$ \\ ${ }^{a}$ Department of Biology, University of Utah, Salt Lake City, Utah, USA; ${ }^{b}$ A.N. Severtsov Institute of Ecology and \\ Evolution, Russian Academy of Science, Moscow, Russian Federation
}

\section{Key Words}

Behavior · Cone snails · Conotoxins · Evolution · Piscivory . Prey shifts $\cdot$ Venoms

\begin{abstract}
The venomous fish-hunting cone snails (Conus) comprise eight distinct lineages evolved from ancestors that preyed on worms. In this article, we attempt to reconstruct events resulting in this shift in food resource by closely examining patterns of behavior, biochemical agents (toxins) that facilitate prey capture and the combinations of toxins present in extant species. The first sections introduce three different hunting behaviors associated with piscivory: 'taser-and-tether', 'net-engulfment' and 'strike-and-stalk'. The first two fish-hunting behaviors are clearly associated with distinct groups of venom components, called cabals, which act in concert to modify the behavior of prey in a specific manner. Derived fish-hunting behavior clearly also correlates with physical features of the radular tooth, the device that injects these biochemical components. Mapping behavior, biochemical components and radular tooth features onto phylogenetic trees shows that fish-hunting behavior emerged at least twice during evolution. The system presented here may be one of the best examples where diversity in structure, physiology and molecular features were initially driven by particular pathways selected through behavior.

(c) 2015 S. Karger AG, Basel
\end{abstract}

\section{Introduction}

A century and a half after Darwin, scientists have established that life's diversity was generated by the gradual splitting of populations and their subsequent divergence in structure, physiology, behavior and other characteristics. Yet, even experts find this process hard to envision because it proceeds on many fronts and through complicated sequences of events that are difficult to reconstruct in detail. Thus, we find ourselves with many endpoints firmly in view, but unable to discern the paths from common ancestors to their derived descendants. The evolution of fish-hunting behavior in venomous cone snails provides a counterexample; the evolutionary histories of their toxin-encoding genes record several key events that gave rise to the present diversity of fish-hunting lineages.

Many authors have suggested that changes in behavior (or other flexible phenotypes) would be expected to precede changes in physiology and structure, by enabling individuals to exploit a new adaptive opportunity in advance of the genetic changes that would later refine and extend the adaptation. This idea traces back at least to Baldwin [1896], and by the end of the 20th century, it had given rise to rich literatures on topics such as phenotypic plasticity and genetic assimilation [reviewed by Crispo, 2007, 2008]. These 'Baldwin effect' processes are widely believed to promote evolutionary diversification, and instances of pres-

\section{KARGER 125}

(c) 2015 S. Karger AG, Base

0006-8977/15/0861-0058\$39.50/0

E-Mail karger@karger.com

www.karger.com/bbe
Baldomero M. Olivera

Department of Biology, University of Utah

257 South 1400 East

Salt Lake City, UT 84112 (USA)

E-Mail olivera@biology.utah.edu 


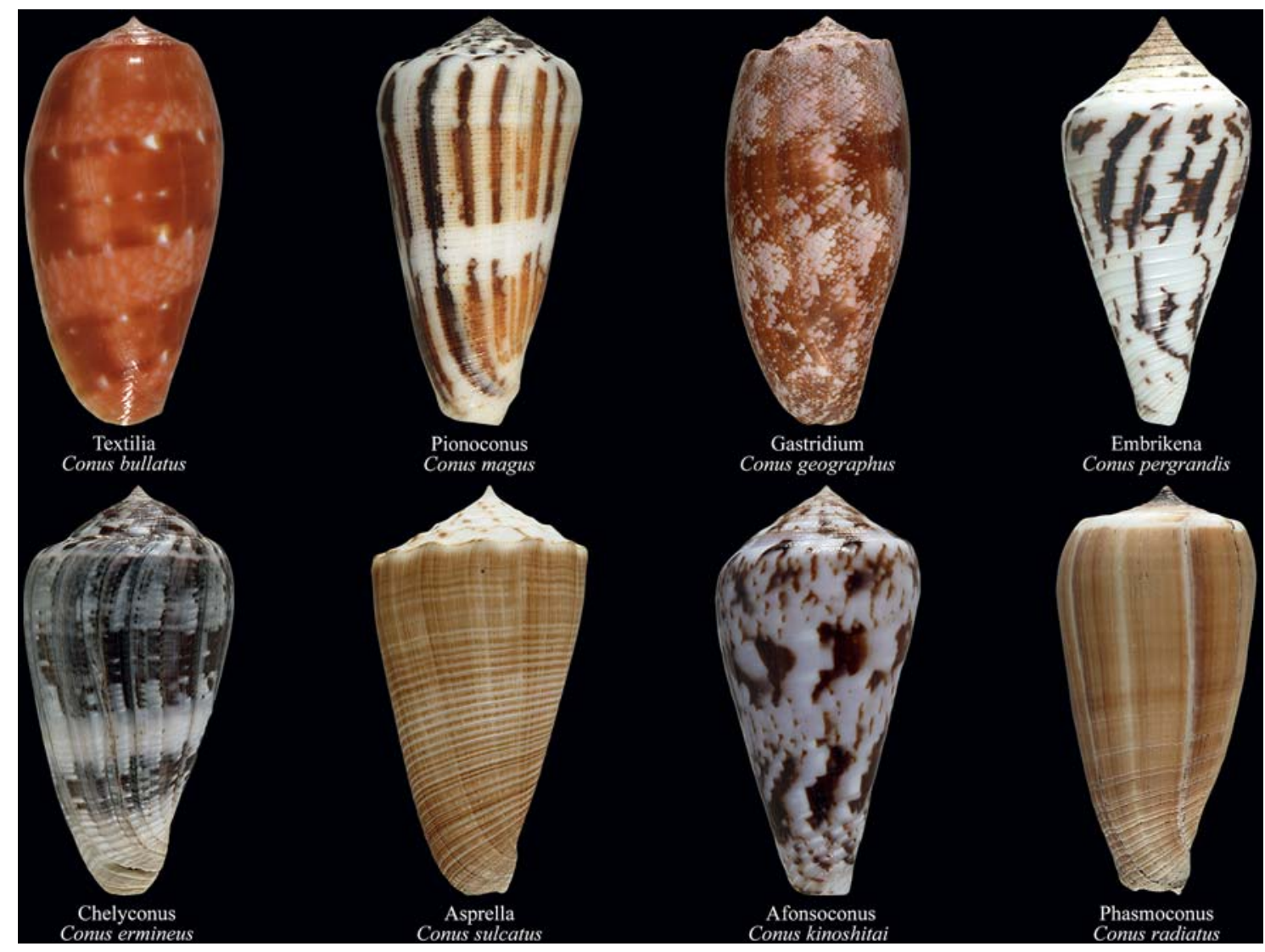

Fig. 1. The eight putative lineages of fish-hunting cone snails illustrated using the shells of the type species of each subgenus believed to be fish hunting.

ent-day plasticity are frequently used to illustrate how learning or other forms of phenotypic flexibility might lead to speciation and higher-order phenotypic divergence of entire lineages. But there appear to be few cases where those macroevolutionary consequences can be demonstrated. Here, we argue that fish-hunting cone snails provide some of the best opportunities to elucidate the role of behavior as a catalyst in the evolution of biochemical, developmental, physiological and ecological diversity.

The ancestors of modern cones hunted worms, as do many extant cone snail species. Increasingly, detailed phylogenetic reconstructions of the Conidae show that some prey specializations found within the family, such as hunting fish and other mollusks, evolved more than once and in some cases through multiple intermediate steps. The phylogenies also show how prey shifts evolved in concert with behaviors, venom delivery methods, venom pharmacologies and other traits. We review the history and diversity of the fish-hunting lineages and attempt to show how what they learned is connected with how they evolved. Because the peptide venoms of cone snails are encoded directly in their genomes, the histories of these key enabling technologies are relatively more straightforward to trace and define than in other lineages. And because cones have radiated so recently and explosively, and their hunting behavior can be observed in the field and even more closely in the laboratory, a sufficiently rich biological context is often available to permit reconstruction of multiple facets of the trajectory of change.

\section{Fish-Hunting Conus: From Behavior to Biochemistry}

\section{Biodiversity of Fish-Hunting Cone Snails}

The cone snails (family Conidae) [Röckel et al., 1995] are venomous, predatory gastropods comprising 750 described species, and of these, probably more than 100 hunt fish. All fish-hunting cone snails can be assigned to the genus Conus, which has been recently subdivided into 57 subgenera [Puillandre et al., 2014a, b] primarily based 
Table 1. Conus subgenera with fish-hunting species

\begin{tabular}{|c|c|c|c|c|}
\hline \multirow[t]{2}{*}{ Subgenus } & \multirow{2}{*}{$\begin{array}{l}\text { Type species } \\
\text { (see fig. 1) }\end{array}$} & \multicolumn{3}{|c|}{ Species, $\mathrm{n}$} \\
\hline & & $\begin{array}{l}\text { total } \\
\text { assigned }\end{array}$ & $\begin{array}{l}\text { supported by } \\
\text { molecular data }\end{array}$ & $\begin{array}{l}\text { envenomation } \\
\text { observed }\end{array}$ \\
\hline Afonsoconus ${ }^{\mathrm{a}}$ Tucker \& Tenorio, 2013 & C. kinoshitai Kuroda, 1956 & 2 & 2 & 0 \\
\hline 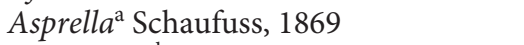 & C. sulcatus Bruguière, 1792 & 8 & 5 & 0 \\
\hline Chelyconus ${ }^{\mathrm{b}}$ Mörch, 1852 & C. ermineus Born, 1778 & 2 & 2 & 2 \\
\hline Embrikena ${ }^{\text {a }}$ Iredale, 1937 & C. pergrandis (Iredale, 1937) & 5 & 1 & 0 \\
\hline Gastridium Modeer, 1793 & C. geographus Linnaeus, 1758 & 6 & 4 & 3 \\
\hline Phasmoconus Mörch, 1852 & C. radiatus Gmelin, 1791 & 75 & 19 & 1 \\
\hline Pionoconus Mörch, 1852 & C. magus Linnaeus, 1758 & 26 & 15 & 8 \\
\hline Textilia Swainson, 1840 & C. bullatus Linnaeus, 1758 & 10 & 4 & 1 \\
\hline
\end{tabular}

a Prey capture has not been directly observed in these lineages. ${ }^{\mathrm{b}}$ Panama and tropical Atlantic in biogeographic distribution (not Indo-Pacific). ${ }^{\mathrm{c}}$ From Puillandre et al. [2014b]. Many of the assignments are 'best guesses' based on shell morphology.

on molecular phylogenetic data (each well-supported lineage has been given subgenus rank). Based on available dietary data, members of eight subgenera feed primarily on fish. Type species of these putative piscivore lineages are shown in figure 1; additional species in each of the eight lineages are figured in the supplemental material (see www.karger.com/doi/10.1159/000438449 for all online suppl. material). The data on species diversity, molecular data and direct observations of fish hunting for each of the eight clades of piscivorous cones is summarized in table 1. For three of the lineages (Chelyconus, Gastridium and Pionoconus), there is a substantial literature documenting their piscivory, and our knowledge about fish-hunting cone snails has come primarily from species in these subgenera [Olivera, 2002]. There is far less published with respect to the piscivory of the other groups, including Phasmoconus, the most species-rich of the eight putative fish-hunting lineages (table 1).

The major adaptive radiation of fish-hunting cone snails has primarily occurred since the Miocene and is focused biogeographically in the Indo-Pacific region. However, one subgenus of piscivorous Conus, Chelyconus, occurs exclusively in the Panamic and tropical Atlantic regions.

\section{Diversity of Behavior Linked to Prey Capture}

Direct observations of piscivorous Conus species envenomating their prey revealed several distinct strategies. The first prey-capture behavior documented for piscivorous Conus in the literature [Kohn, 1956] is what we will call the 'taser-and-tether' strategy (previously referred to as the 'hook-and-line' or 'harpoon strategy' [Olivera,
2002]). As with a taser, this strategy relies on electrical stunning power provided by venom components acting on the fish's nervous system. Once a piscivorous cone snail detects a fish (primarily through chemosensory cues), it becomes much more active and moves towards the fish. At some point, the snail extends its rostrum (a massive funnel formed by the muscular walls of the proboscis sheath in the anterior part of the head), and a long, thin, distensible proboscis is extended out of the rostrum (fig. 2). For many fish-hunting Conus species, the proboscis can be greatly extended, typically several times greater than the length of the shell. When the proboscis tip is sufficiently close to potential prey, a harpoon-like radular tooth shoots out to pierce the skin of the fish.

Typically, the gastropod radula is a flexible membrane with multiple chitinous plates (or teeth) arranged in transverse rows. However, in cone snails, the radula has undergone a profound evolutionary change: the membrane is reduced and teeth are transformed into hollow harpoons, often barbed at their tips. At the moment of attack, the distal end of the tooth is grasped by strong circular muscles at the tip of the proboscis, the radular tooth is injected through the scales and skin of the fish, and venom is propelled through the hollow tooth - in effect it is an injection by hypodermic needle [Schulz et al., 2004; Salisbury et al., 2010].

In Conus species that use the taser-and-tether strategy, the harpoon-like tooth is equipped with the strongly barbed accessory process that tethers the targeted fish securely. After a successful strike, the snail reels in the fish (fig. 2) by the retracting proboscis until it can be completely engulfed by the rostrum, which in some species also 
Fig. 2. The taser-and-tether strategy for prey capture. a-d A specimen of Conus catus envenomating its fish prey. The cone snail extends its yellowish proboscis towards the fish (a), subsequently strikes the fish (b) and immediately begins to retract its proboscis, and the fish is tethered through the radular tooth (see text). Within a few seconds, the fish is tetanically paralyzed with very stiff fins (c), and in this state, it is engulfed by the rostrum of the snail, where predigestion takes place (d). In approximately $2 \mathrm{~h}$, the snail will regurgitate the scales and the bones of the fish, as well as the harpoon-like radular tooth that it used for injecting venom; all the softer parts of the envenomated fish go further down into the gut for complete digestion (taken from a video supplied by Prof. Jason Biggs, University of Guam). e Shells of different species and subgenera that have been directly observed to use the taser-andtether fish-hunting behavior. Shells of species of cone snails in the subgenus Pionoconus (table 1). Top row, left to right: C. striatus (Oahu, Hawaii); Conus circumcisus (Olango Island, Philippines); Conus stercusmuscarum (Bohol Island, Philippines). Middle row, left to right: Conus consors, form turschi (Bali, Indonesia); C. catus (Nuku Hiva, Marquesas Islands) and $C$. monachus (Marinduque Island, Philippines). Bottom row: Conus striolatus (Cebu Island, Philippines) and Conus magus (Bicol Peninsula, Luzon Island, Philippines). Pionoconus is the subgenus that has most frequently been observed to envenomate their prey by the taser-and-tether strategy. f Cone snail species in other lineages of $\mathrm{Co}$ nus directly observed to use the taser-andtether strategy. Top: C. bullatus, Textilia clade (Olango Island). Middle row, left to right: C. purpurascens (West Mexico) and C. ermineus (Senegal, West Africa), both in the Chelyconus clade. Bottom: C. obscurus, Gastridium clade (Oahu).
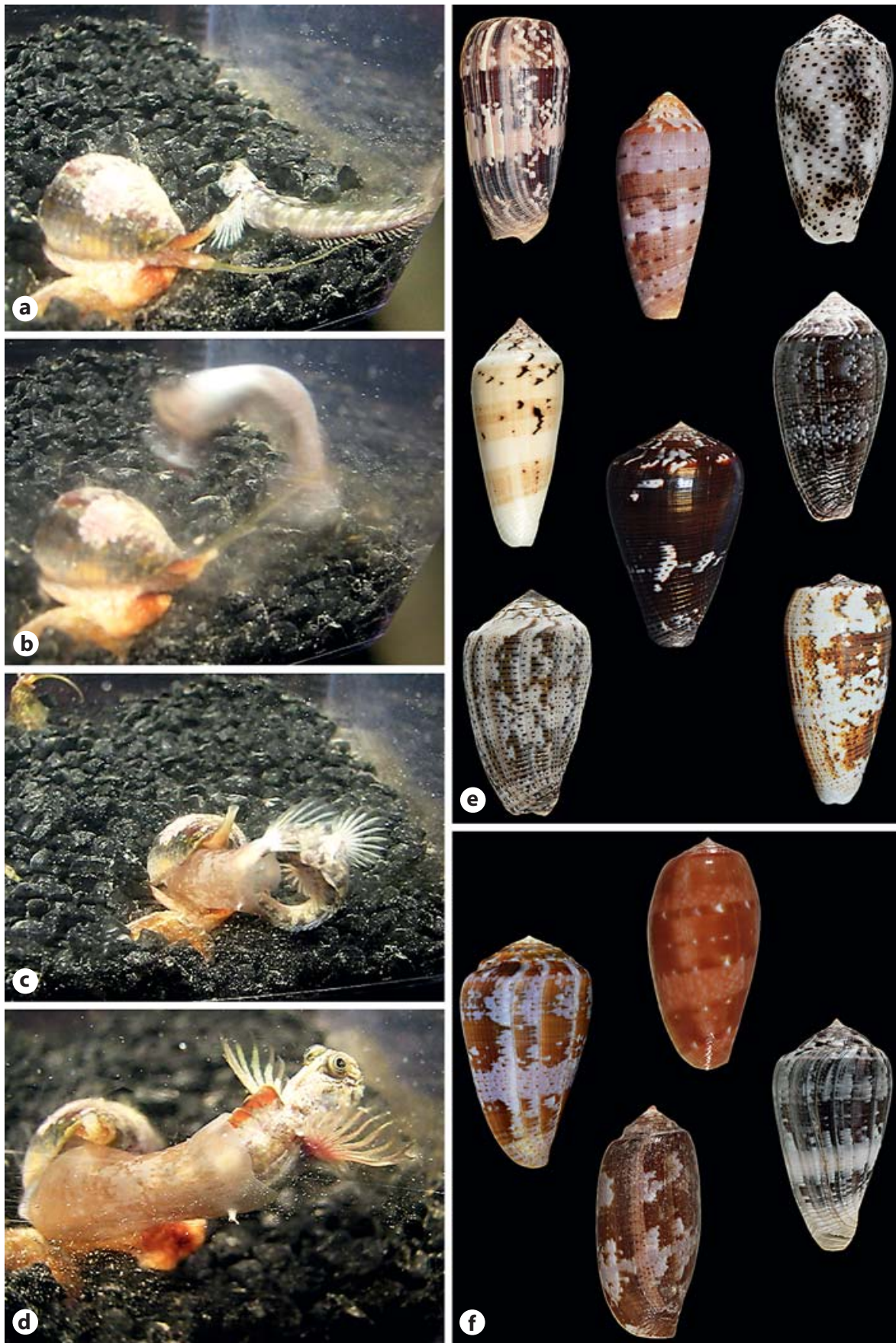

serves as a predigestion chamber. One to two hours after capturing the fish, the snail will typically regurgitate the fish scales and bones along with the harpoon-like tooth.

After a strike, the fish prey is almost immediately immobilized in a tetanic paralysis, with all of its fins fully extended. The fish is typically engulfed by the snail in this state (see online suppl. videos showing this prey-capture strategy). However, in a few cases, the fish recovered from the paralysis before it could be completely reeled into the rostrum and was able to break loose. When this happens, the cone snail always does a search, apparently expecting to find a paralyzed fish. The neurobiology underlying these behavioral observations will be detailed in the next section. 
Fig. 3. The net-engulfment strategy. Shown are the two Conus species observed to use the net-hunting strategy, C. geographus (ac) and C. tulipa (d-f). As soon as these species detect a fish, they extend and greatly expand their rostrum towards the fish. $C$. tulipa has ciliary processes at the edges of its rostrum. The snails of both species always engulf the fish prey before they inject venom. Unlike the taser-and-tether strategy shown in figure 2, they do not extend their proboscis outside the rostrum to envenomate prey. The ability of C. geographus to engulf fish is in part due to the release of venom components into the water that cause both sensory deprivation and hypoglycemia (see text).
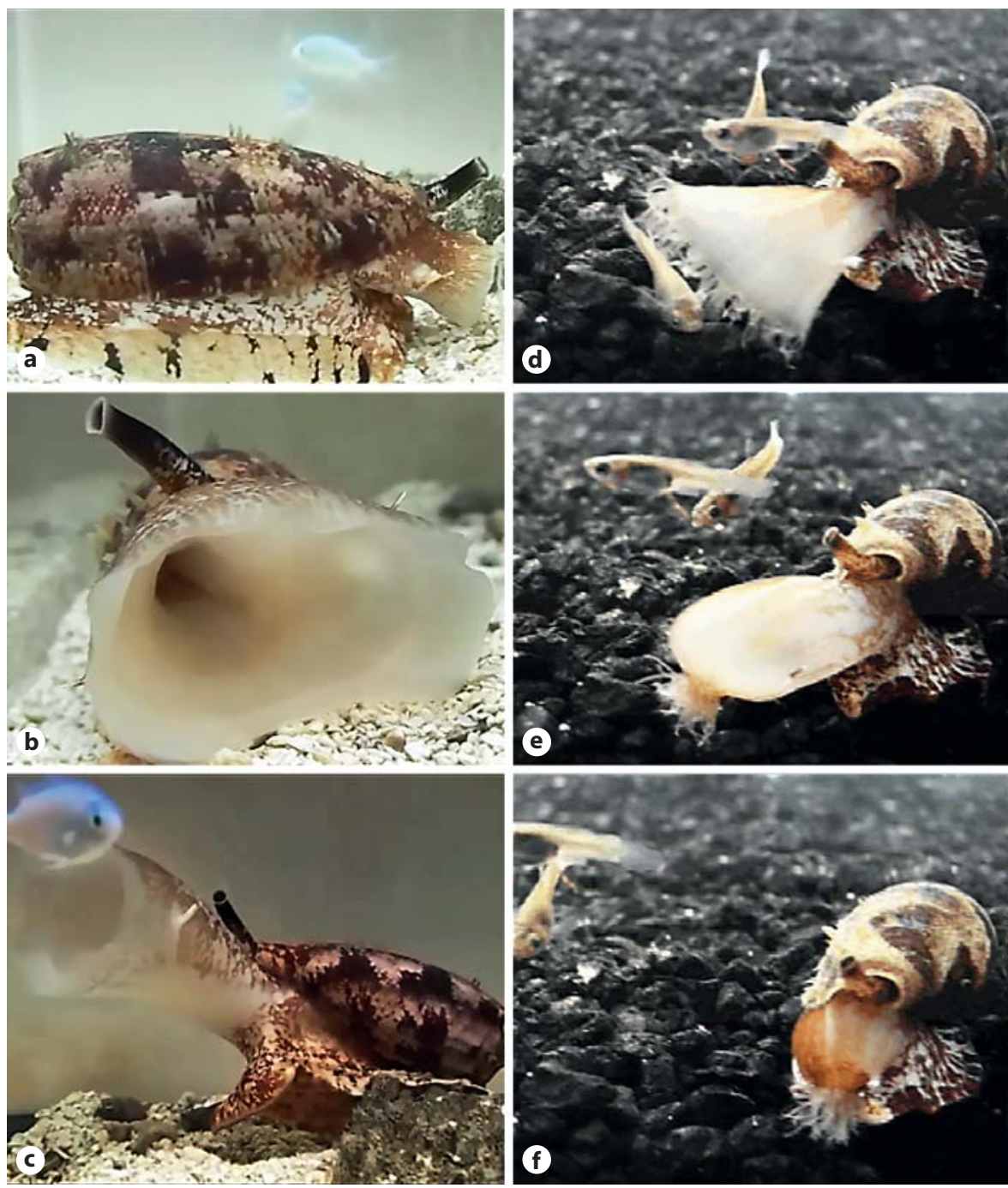

A very different 'net-engulfment' (or simply 'net') strategy is used to engulf several prey fish at once, much as a fishing net captures multiple fish. The net strategy has been observed in two closely related species, Conus geographus and Conus tulipa of the subgenus Gastridium [Olivera and Cruz, 2001; Olivera, 2002; Olivera et al., 2014]. The behavior of these fish-hunting snails is strikingly different from the taser-and-tether strategy described above; after detecting a fish, instead of extending their proboscis, these snails open up their extremely large, cavernous rostrum (fig. 3). They carefully approach the fish, directing the open end of the rostrum towards the potential prey. These two species always engulf the fish by the rostrum before venom is injected through the proboscis and radular tooth. Once the fish are completely engulfed within the rostrum of the snail, envenomation and predigestion take place. Invariably, these snails also regurgitate the scales and bones of the fish, as well as the radular tooth used for injecting venom.

It has been suggested that in the wild the net-engulfment strategy is primarily used to prey on schools of small fish hiding in reef crevices at night [Olivera, 2002]. This hypothesis is consistent with aquarium observations: these snails try to engulf multiple fish if available, whereas the taser-and-tether strategy used by other snails only targets one fish at a time. Thus, if a Conus species using the latter strategy misses its target, it usually does not attempt another strike within the same day. In contrast, after a fish is fed to C. geographus or C. tulipa, the snail is immediately prepared to engulf a second fish. In an aquarium, a specimen of C. geographus can be fed one fish after another, with the snail readily opening its rostrum 

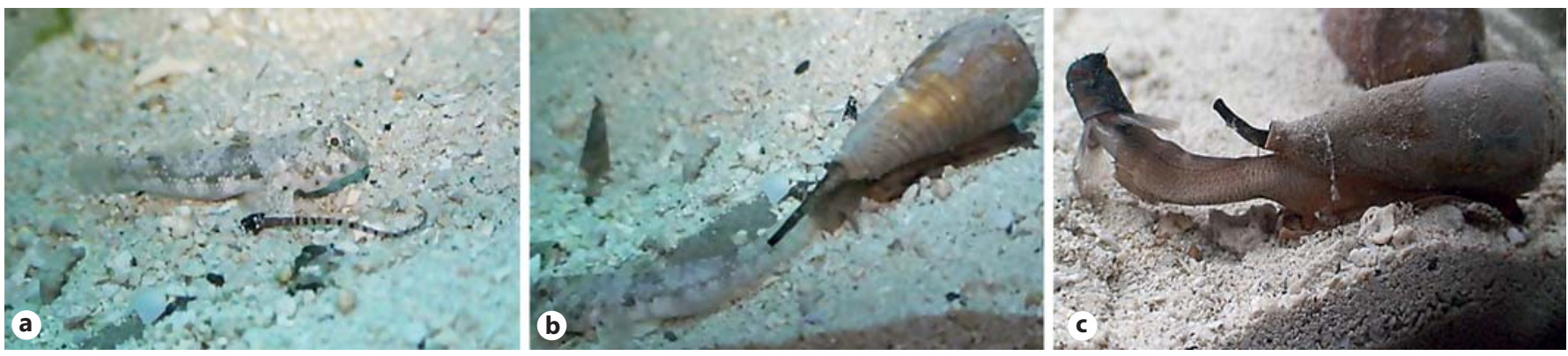

Fig. 4. The strike-and-stalk strategy for prey capture. Shown is a specimen of $C$. flavus envenomating its prey. Once the cone snail has detected the presence of a fish, it extends its strikingly striped proboscis and flails it around, resembling the arms of a brittle star. When the tip of the proboscis gets close to the fish, it stings the fish but does not tether it. After envenomating its prey, the snail, which was buried in (a), unburies itself and begins to follow the fish (b). Once the fish is immobilized, the snail engulfs it completely (c). Two instances of envenomation were observed for C. flavus. In the first, there was apparently an insufficient amount of venom injected, and the snail followed the fish around for many minutes, but the fish never was completely immobilized. In the second, after envenomation, the fish was immobilized quickly upon envenomation and began to tremble and stiffen its musculature. The snail engulfed it from the tail first. These observations suggest that these snails have some components of the lightning-strike cabal (described in the text for the taser-and-tether strategy).

ing, which we will refer to as the taser-and-tether, netengulfment and strike-and-stalk strategies.

\section{Neurobiological Mechanisms Underlying}

Prey-Capture Strategies

The neurobiological mechanisms underlying the taser strategy are well understood. In this strategy, two distinct physiological circuits of prey are targeted by venom components [Terlau et al., 1996; Olivera, 1997]. One set of venom components, known as the lightning-strike cabal', causes a massive depolarization of axons at the injection site and also inhibits the desensitization of postsynaptic receptors in peripheral sensory circuitry. This triggers an 'electrical storm' in the nervous system of the envenomated fish and, after a good strike, results in tetanic paralysis of the fish within seconds. A second group of toxins in the venom, known as the 'motor cabal', are disseminated through the body of the prey, presumably through the circulatory system of the fish. Together, the venom components of the motor cabal potently inhibit neuromuscular transmission, resulting in an irreversible paralysis of the skeletal musculature.

The taser-and-tether strategy has been the most widely observed in nature, with direct recordings for a diversity of Conus species, encompassing four different subgenera; these are shown in figure 2. It was first characterized in Conus purpurascens, and studies on the venom of this species provided the first data on the underlying neurobiological mechanisms [Terlau et al., 1996]. As will be detailed later, the strategy is clearly widespread phyloge- 
netically across the genus, encompassing multiple subgenera.

Although the net-engulfment strategy has been documented only in two species, C. geographus and C. tulipa, its molecular basis is also well studied. C. geographus is arguably the most intensively investigated of all Conus [Terlau and Olivera, 2004; Hu et al., 2012]. The special interest in C. geographus is a result of several dozen recorded human fatalities from its sting. It was the first cone snail venom investigated at a biochemical and molecular genetic level [Olivera et al., 1985, 1990], and at present the behavior of the snail and the physiological effects and biochemical components of the venom can be integrated to provide a comprehensive description of the mechanisms that underlie the envenomation process.

C. geographus appears to be a highly specialized piscivorous Conus species that has evolved the ability to successfully capture multiple fish at one time, in contrast to species that use other strategies and can target only one fish at a time. By contrast with the taser-andtether strategy for which the venom is released only once, the Conus species which employ the net-engulfment strategy release venom components several times, and the composition of venoms released in the initial stage of feeding, and at its final stage, when the fish is injected, is different. A major innovation found in $C$. geographus venom (and probably in C. tulipa, though this is less well established) are the so-called 'nirvana cabal' components (table 2), which make the fish seem sedated and dazed or disoriented, as if under the influence of narcotic drugs. This subset of venom components is highly expressed in the region of the venom duct closest to the pharynx [Safavi-Hemami et al., 2014], and these are the very first components released as the snail stalks its prey.

Several toxins in the nirvana cabal (table 2) are postulated to inhibit sensory circuitry, among them the conantokin that inhibits NMDA receptors [Mena et al., 1990; Donevan and McCabe, 2000] and contulakin-G, an analogue of neurotensin [Craig et al., 1999a, b; Lee et al., 2015]; both of these relatively small peptides are characterized by a high frequency of posttranslationally modified amino-acid residues. A most surprising component of the nirvana cabal, discovered only recently, is a specialized insulin that is smaller than any other known insulin and is most similar to the endogenous insulin of fish in its primary amino-acid sequence [Safavi-Hemami et al., 2015].

In the initial stage of prey capture, the net-hunting snail approaches the fish and releases a selected subset of venom components directly into the water. Penetrating the fish circulatory system presumably by uptake through the gills, these secreted venom components cause disorientation and a hypoglycemic state in all fish that are in close proximity to the foraging cone snail. As the school of fish becomes both sensory deprived and hypoglycemic, the snail opens its rostrum and attempts to engulf one or several fish at a time. It appears to have a higher probability of success because the nirvana cabal venom components have acted on all of the fish in the school. After the fish are captured, the mollusk injects each individual fish as in the taser-and-tether strategy, but with one notable difference: the fish are not tethered. In these circumstances, with prey fish already engulfed and sedated, there is little risk of escape or struggle, and probably for this reason the radular tooth is not physically attached to the snail upon injection. Here, we see a striking example of how behavior, capturing fish with nets, correlates with loss of a physical structure, the tether, in addition to evolution of selective biochemical agents, the nirvana cabal conopeptides.

The injected venom of C. geographus contains the motor cabal components. Among the motor cabal conopeptides are some of the most well-characterized peptides from cone snail venoms, including $\omega$-conotoxin GVIA [Olivera et al., 1984; Feldman et al., 1987; Yarotskyy and Elmslie, 2010], which inhibits voltage-gated calcium channels at the presynaptic terminus, $a$-conotoxin GI [Gray et al., 1981; McManus and Musick, 1985], which inhibits the postsynaptic nicotinic receptor, and $\mu$-conotoxin GIIIA [Cruz et al., 1985, 1989], which inhibits voltage-gated sodium channels on the sarcolemma (table 2).

The strike-and-stalk strategy, recorded to date in a single species of Conus, remains the least studied. In behavioral aspects, it is obviously closer to the taser-and-tether strategy, as the prey is envenomated only once, prior to being engulfed. However, the detailed neurobiological mechanisms that underlie this strategy remain largely undefined (although it seems likely from the initial behavioral observations described previously that lightningstrike cabal components are involved).

\section{Biochemistry, Pharmacology and Molecular Genetics}

A record of events occurring during the evolution of hunting behaviors is partially preserved in the genes encoding venom components. The major components of cone snail venoms are disulfide-rich peptides, and specific examples for some of the venom components of C. geographus used to capture fish are shown in table 2 . The major- 
Table 2. Venom components of C. geographus venom

\begin{tabular}{ll}
\hline Peptide & Gene Mechanism [reference] Amino acid sequence (mature venom peptide) \\
super- \\
family
\end{tabular}

Nirvana cabal peptides

Conantokin-G B1

$\sigma$-Conotoxin $\quad S \quad$ 5HT3 antagonist [England et al., 1998]

Contulakin-G C Neurotensin receptor agonist

[Craig et al., 1999a, b; Lee et al., 2015]

Con-Ins GI $\quad$ - $\quad$ Insulin receptor

[Safavi-Hemami et al., 2015]

Lys-conopressin-G -

Vasopressin receptor [Cruz et al., 1987]

Motor cabal peptides

$\mu$-GIIIA

M

Voltage-gated $\mathrm{Na}$ channel $\left(\mathrm{Na}_{\mathrm{v}} 1.4\right.$

subtype) [Cruz et al., 1985, 1989]

$\omega$-GVIA

$\mathrm{O} 1$

Voltage-gated Ca channel $\left(\mathrm{Ca}_{\mathrm{v}} 2.2\right.$

subtype) [Olivera et al., 1984]

$\alpha-\mathrm{GI}$

A
Nicotinic acetylcholine receptor (adult muscle subtype) [Gray et al., 1981]
GE $\gamma^{a} \gamma \mathrm{LQ} \gamma \mathrm{NQ} \gamma \mathrm{LIR} \gamma \mathrm{KSN}$

GCTRTCGGO $^{`}$ KCTGTCTCTNSSKCGCRYNVHPSG $(B r W)^{\mathrm{d}}$ GCGCACS*

Z $^{\text {bSEEGGSNAT }}{ }^{\S}$ KKPYIL

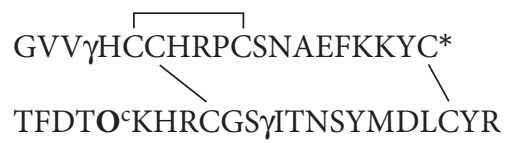

CFIRNCPKG*

Posttranslational modifications: ${ }^{\mathrm{a}} \gamma=\gamma$-carboxyglutamate; ${ }^{\mathrm{b}} \mathrm{Z}=$ pyroglutamate; ${ }^{\circledR} \mathrm{T}=O$-glucosylation of threonine with $\beta$-D-Gal$(1 \rightarrow 3)$ - $\alpha$-D-GalNAc- $(1 \rightarrow)$ disaccharide; ${ }^{\mathrm{C}} \mathbf{O}=$ hydroxyproline; ${ }^{\mathrm{d}} \mathrm{BrW}=6$-bromotryptophan; ${ }^{*}=\mathrm{C}$-terminal amidation; - = no superfamily assigned.

ity of these are relatively small peptides, with 12-30 aminoacid residues, and with 2-3 disulfide cross-links. Many of the peptides have unusual posttranslational modifications [Craig et al., 1999a, b]; examples found in the C. geographus venom components shown in table 2 include $\gamma$-carboxyglutamate found in the conopeptide conantokin-G and $O$ glycosylated threonine in contulakin-G.

Each venom peptide is encoded by a specific gene [Woodward et al., 1990] in the cone snail genome, and these genes are specifically expressed (sometimes at very high levels) in the secretory cells that line the venom duct. The messenger RNAs encoding these peptides are conventionally translated by ribosomes. The initial translation product is a larger precursor, typically $70-100 \mathrm{ami}-$ no-acid residues in length, with a well-defined signal sequence region, an intervening region, the propeptide, and, always in single copy, the mature toxin region at the carboxy-terminus. After translation, the precursor polypeptide crosses into the endoplasmic reticulum, and spe- cific amino-acid residues in the mature toxin region may be posttranslationally modified. Ultimately, the mature peptide toxin is generated by proteolytic cleavage.

The genes that encode Conus venom peptides exhibit an unprecedented rate of accelerated evolution through a mechanism that has been referred to as 'focal hypermutation' [Olivera et al., 1990; Duda and Palumbi, 1999; Olivera et al., 1999; Conticello et al., 2000, 2001], and each Conus species expresses its own distinct complement of venom peptides. This means that while particular venom peptide genes belonging to certain gene superfamilies are consistently distributed among several Conus lineages, the genes harbored by any given species are unique and not found in the exact same form in other, even closely related species. However, if the precursor sequences are compared across species, it is found that the signal sequences are remarkably conserved within a single gene superfamily, and the propeptide regions are more conserved than the mature toxin sequences [Woodward et al., 1990; Espiritu et 
al., 2001; Santos et al., 2004], albeit not as conserved as the signal sequences. The diversity seen for mature venom peptides, contrasted by conserved propeptide and signal sequence regions, is analogous to the generation of molecular diversity for antibodies in the mammalian immune system, except that the toxin-encoding genes are fixed in the germline and not somatically generated. In this analogy, the conserved regions of the venom peptide precursors correspond to the constant regions of antibodies, including the signal sequence, the propeptide region and the cysteine residues of the mature toxin, which together determine the overall structure of the conopeptide by guiding which specific disulfide cross-links are established. The amino-acid residues located between cysteine residues correspond to the hypervariable region, and, analogous to antibodies, the variable residues determine target specificity and potency. In both cases, structure is conserved even as new binding specificity is rapidly generated

The classification of the conopeptides is based on the sequence of the conserved signal region; the set of gene products sharing the same signal sequences is assigned to one gene superfamily. A small number of gene superfamilies encoding venom peptides are highly expressed in all fish-hunting Conus species. In particular, the A, M and O1 gene superfamilies (see table 2 for an example of each) are predominant and account for the majority of highly expressed peptides found in the venoms of fish-hunting $\mathrm{Co}$ nus. As noted above, this apparent biochemical uniformity disguises the great pharmacological diversity that has been generated within a single gene superfamily through the adaptive radiation of the fish-hunting Conus lineages.

It appears that each individual venom peptide has very specific targeting selectivity for a particular pharmacological site in the envenomated animal. One example of the precise biochemical interactions that provide both high affinity and high selectivity has been elucidated in a crystal structure of a conopeptide bound to its target receptor [Chen et al., 2014]. Biochemical determinants important for potency and selectivity of the venom peptides targeted to diverse nicotinic acetylcholine receptors have recently been reviewed [Teichert et al., 2015].

\section{Anatomy and Phylogeny}

The Diversity of Harpoons in Fish-Hunting Cones:

Anatomical Correlates of Individual Behavioral

Strategies

The morphology of the hollow radular teeth used for venom injection varies considerably among fish-hunt- ing Conus species and provides an important clue as to prey-hunting behavior. Figure 5 compares different radular tooth morphologies. The tooth proportions, tip morphology, and the position and extent of serration, all vary in different piscivorous Conus species, and many of these morphological features can be correlated with the different behavioral subclasses described above. Thus, individual species in the Conus subgenera that were shown to use the taser-and-tether strategy have strong radular teeth with a long accessory process, often bearing an additional barb that can tether fish securely after a successful strike (fig. 5a-d) [Duda et al., 2001; Schulz et al., 2004; Tucker and Tenorio, 2009]. In contrast, the larger species of Gastridium that employ a net strategy (C. geographus and C. tulipa) have needle-shaped harpoons with a narrow base and are very weakly barbed at their tip (fig. 5f). Remarkably, the smallest Gastridium species, Conus obscurus, which employs the taser-andtether strategy, has a harpoon with a strong accessory process, similar to those in Chelyconus, Pionoconus and Textilia (fig. 5g, h).

While the type of radular tooth with an accessory process is found in many species of the Phasmoconus clade (for example, Conus asiaticus, C. mucronatus and C. sertacinctus; fig. 5d), other Phasmoconus species, including the type species, Conus radiatus, have stouter harpoons that in proportions and tip weaponry rather resemble harpoons of worm-hunting Conus species (fig. 5e).

Weakly barbed harpoons are found in species of the putative fish-hunting clades Asprella (fig. 5i) and Afonsoconus (fig. $5 \mathrm{j}$ ), though these are completely different from the ones in larger Gastridium. Their morphology is hardly distinguishable from one another, and in overall structure they are closer to radulae of some vermivorous subgenera than to radulae of other groups of fish-hunting cones. Nonetheless, the phylogenetic analysis shown in figure 6 [Puillandre et al., 2014b] demonstrates a closer affinity of Afonsoconus to Textilia and Pionoconus.

Thus, a diversity of radular morphologies has been documented for two subgenera, Phasmoconus and Gastridium, establishing that the structure of radulae is not strictly correlated with the molecular phylogeny. Conversely, the described differences in radular morphology suggest an evolutionary flexibility and the adaptive potential of radula. Closely related Conus species may diverge rapidly in their radular morphology, presumably depending on changes in the hunting behavior that they employ. Conversely, distantly related fish-hunting species may develop strikingly similar radular teeth morphology convergently, if they evolve the same mechanism
66

Brain Behav Evol 2015;86:58-74 DOI: $10.1159 / 000438449$
Olivera/Seger/Horvath/Fedosov 


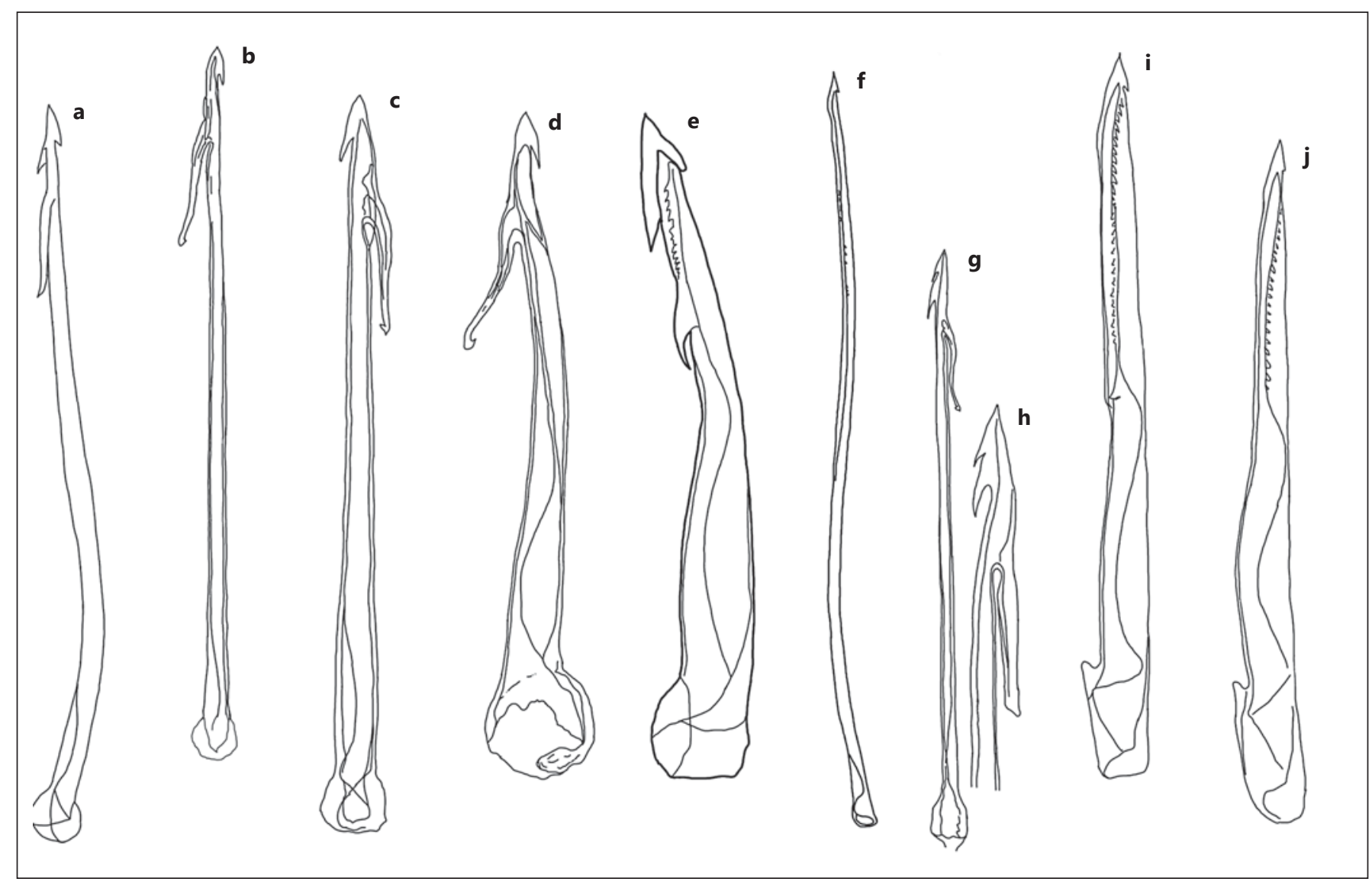

Fig. 5. Diversity of radular teeth in different lineages of fish-hunting cones [reproduced from Tucker and Tenorio, 2009]. The radular teeth of the eight type species of piscivorous subgenera are shown. For the subgenera Phasmoconus and Gastridium where there is clearly a heterogeneity in radular tooth morphology; di- verse types are shown. a C. ermineus (Chelyconus). b C. magus (Pionoconus). c C. bullatus (Textilia). d C. asiaticus (Phasmoconus - not type species). e C. radiatus (Phasmoconus). f C. geographus (Gastridium). g, h C. obscurus (Gastridium - not type species). i C. sulcatus (Asprella). j Conus kinoshitai (Afonsoconus). of prey capture, as is apparently the case for species in the Pionoconus and Chelyconus lineages.

\section{Phylogeny and Plasticity in Prey-Capture Strategies}

This discussion of behavior in a phylogenetic context is based on fragmentary data at the present time and is necessarily somewhat speculative. A pattern consistent with behavioral plasticity emerges if prey-capture strategies are considered in the context of known phylogenetic relationships. A comprehensive molecular phylogeny for the family Conidae has recently been published [Puillandre et al., 2014a]. The section of the published phylogenetic tree that contains the eight putative piscivorous Conus subgenera is detailed in figure 6; the available molecular phylogeny at the species level is shown in online supplementary figures $1-5$. Several features of the tree are notable: some subgenera are species rich (such as Phasmoconus, with 75 assigned species), while other lineages appear to comprise only a few species (Chelyconus and Afonsoconus, with only two species each). Although relationships between the subgenera are not definitively established, Chelyconus appears separate from all other putative piscivorous subgenera, with the IndoPacific worm-hunting lineage Virroconus as its sister taxon (fig. 6; online suppl. fig. 5). For over 80 of the 134 species listed in these eight putative piscivorous subgenera by Puillandre et al. [2014b], the assignments were based on shell or radular morphology, without supporting molecular information. As described above, direct behavioral observations on envenomation are completely lacking for three of the subgeneric groups, and even for the most species-rich clade (Phasmoconus), 


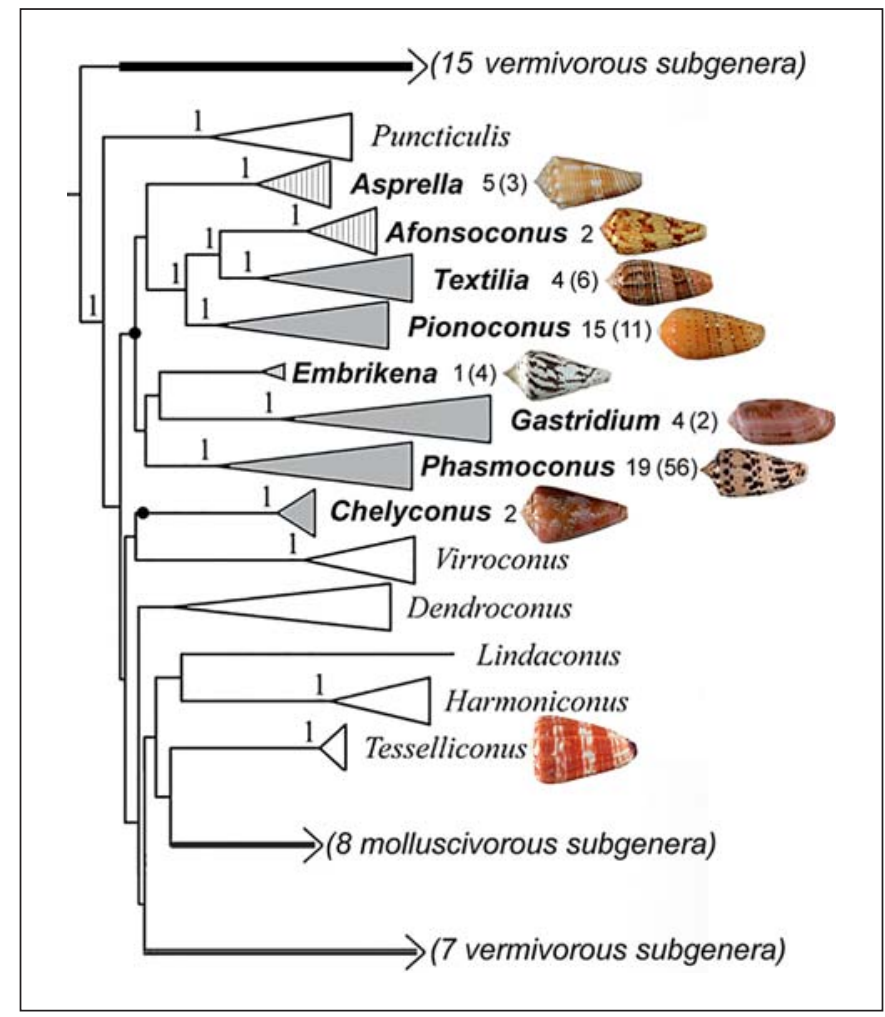

Fig. 6. Phylogenetic tree. The portion of the Conus phylogenetic tree showing the eight subgenera believed to be fish hunting (in bold type). The subgenera indicated in dark triangles are confirmed to have at least one fish-hunting species from direct observation of envenomation. The triangles with stripes are the three lineages of putative fish-hunting cone snails where there has been no direct observation of prey capture. The white triangles are worm-hunting subgenera. The relationship of the piscivorous Conus lineages to molluscivorous and the most closely related vermivorous subgenera is shown. The numbers shown next to the fish-hunting lineages are the number of species in each lineage directly analyzed for molecular markers; the number in parentheses is the number of additional species in that lineage estimated by Puillandre et al. [2014a]; for these additional species, no molecular data were available. For each of the fish-hunting subgenera, the shell of one species is shown: Asprella (Conus sulcocasteneus); Afonsoconus (C. kinoshitai); Textilia (Conus dusaveli); Pionoconus (Conus floccatus); Embrikena (Conus pergrandis); Gastridium (Conus eldredi); Phasmoconus (Conus blanfordianus); Chelyconus (C. purpurascens). We also show an example of a species observed to hunt fish in the primarily worm-hunting subgenus Tesseliconus (C. tessulatus).

only one of 75 species has been observed to envenomate its fish prey.

The data suggest that within some of the piscivorous lineages of Conus, different prey-capture strategies have evolved. This is most well established in the Gastridium clade (online suppl. fig. 3), where the two largest species use a net-engulfment strategy, while the smallest species (C. obscurus) uses the taser-and-tether strategy [Olivera et al., 2014]. Thus, a divergence in the prey-capture strategy in the subgenus Gastridium is securely based both on direct observation and divergence in radular morphology.

If radular morphology is truly indicative of the preycapture strategy used, then it would appear that while species in Pionoconus, Chelyconus and Textilia use the taser-and-tether strategy exclusively, Phasmoconus, the subgenus with the largest number of species, may be heterogeneous. The only direct observations that have been made established that $C$. flavus uses the strike-and-stalk strategy (fig. 4). The radular morphology of many Phasmoconus species is consistent with a similar strategy, but, as described above, some Phasmoconus species have a radular morphology that suggests that they use the taserand-tether strategy. Thus, the heterogeneity in the morphology of the radular tooth makes it likely that, as in Gastridium, there is a corresponding heterogeneity in the prey-capture strategies employed by the $\sim 75$ species of Phasmoconus.

Other indicators of which prey-capture strategy is employed are the components of the venom. Thus, conantokins that target vertebrate NMDA receptors have been postulated to be a major component of the nirvana cabal. Among the Conus species that hunt fish, these types of peptides were first characterized from the venoms of $C$. geographus [McIntosh et al., 1984] and C. tulipa [Haack et al., 1990], the two species that use the net-engulfment strategy. Conantokin peptides have been identified as prominent venom components in species of the Asprella clade [Twede et al., 2009; Gowd et al., 2010, 2012]. Although none of the species in this clade have been directly observed to envenomate fish, the high expression levels of conantokins in their venoms suggest that they may also use a net-engulfment strategy to prey on fish. The analysis of gut contents of one species, Conus sulcatus, provided direct evidence that this clade is indeed fish hunting [Kohn A., pers. commun.].

\section{Approaching Potential Prey: Diverse Solutions and Adaptations}

A general challenge that all fish-hunting cone snails face is getting close enough to envenomate potential prey. One common strategy appears to be to ambush fish at night as they hide from predators such as sharks. Many piscivorous cone snails have a very long, translucent proboscis that they can extend towards a fish hiding under a rock or in a hole in the coral reef. However, fish-hunting 
Fig. 7. Diverse-colored proboscis extended to hunt fish. The panels show six species of cone snails that extended their proboscis in response to the presence of a fish. The species shown are: C. consors (a); C. flavus (d); C. circumcisus (b); C. monachus (e); C. purpurascens (c) and C. tessulatus (f). C. consors, C. circumcisus and C. monachus are species in the subgenus Pionoconus (fig. 1, 6; table 1). C. flavus is in the subgenus Phasmoconus, while C. purpurascens is in the subgenus Chelyconus. C. tessulatus is not in one of the specialized fish-hunting subgenera; it belongs to the subgenus Tesseliconus, which is primarily worm hunting, but will opportunistically attack fish, although it is often unable to pierce fish skin (see text).
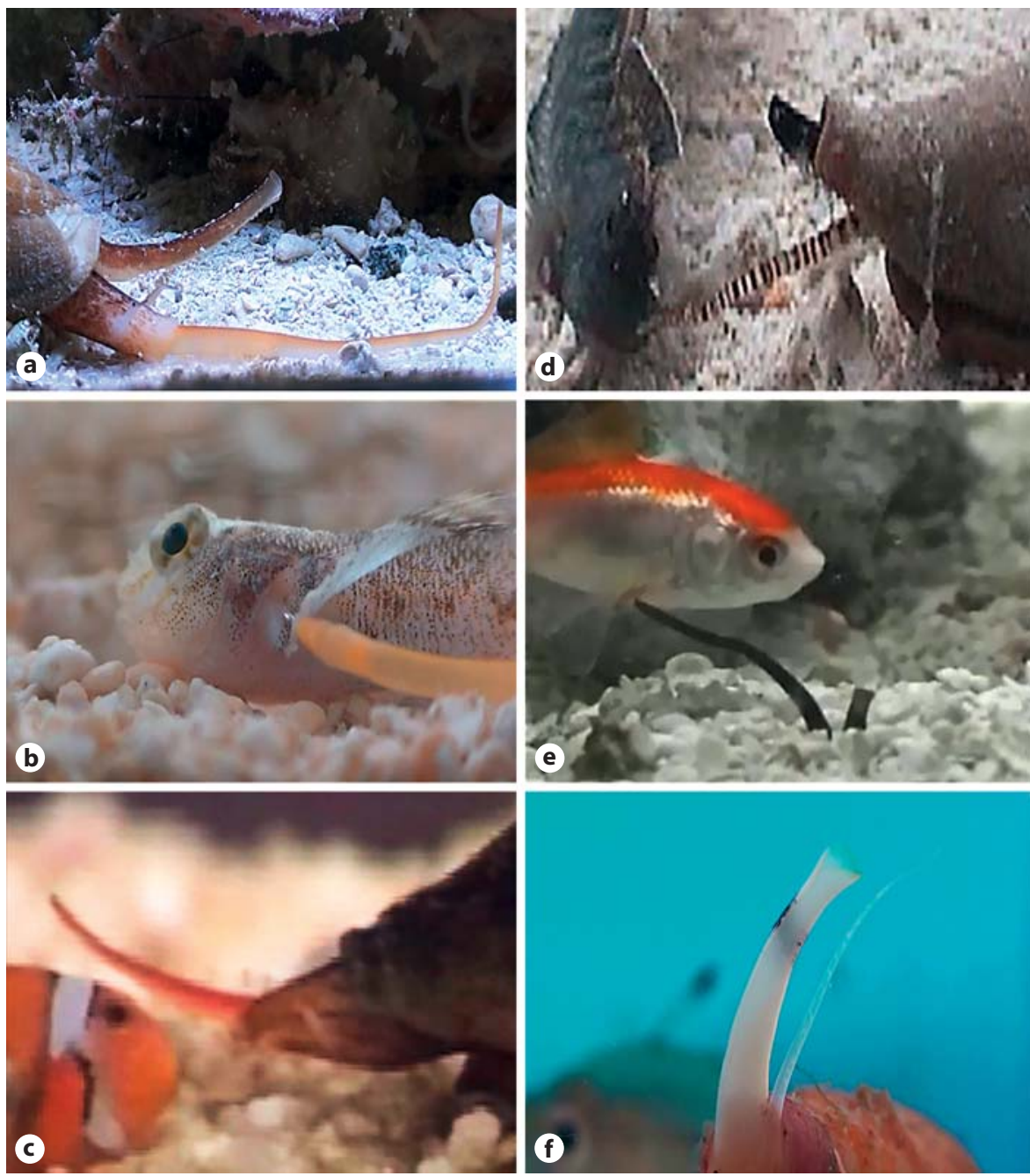

cone snails vary considerably in the color of their proboscis. This diversity suggests that there may be selection for a specific color or pattern observed in a given cone snail species. Some of the diversity in the proboscis of cone snails is illustrated in figure 7; in the examples shown, all of the snails extended their proboscis in response to the introduction of a fish into the aquarium. As noted above, many cone snails have a translucent proboscis such as is shown for Conus tessulatus. In contrast, however, some of the other species have evolved a brightly colored or strongly patterned proboscis.

In some cases, color may actually help in making the extended proboscis more cryptic. Conus monachus has a deep black proboscis. This species tends to live on muddy substrates, and therefore the dark coloration could make the proboscis more difficult to detect as it is extended (as does its dark shell). As described above, the unique, strikingly striped proboscis of C. flavus may resemble the arms of a brittle star, disguising the proboscis in environments with many brittle stars. This might lead the fish to ignore it, allowing the snail to strike at a nearby fish. Although this is conjecture at this point, the evolution of such an unusual and striking pattern on the proboscis seems likely to have some adaptive advantage. The same type of general explanation has been suggested for the diverse patterns found on the shells of different $\mathrm{Co}$ nus species (fig. 1); the patterning may make them more cryptic against the background, facilitating their approach to fish without being detected (similar to the standard explanation for stripes on a tiger or spots on a leopard).

In a few cases, however, crypsis is clearly not the explanation. In an aquarium, C. purpurascens will extend its bright red proboscis, and the authors have observed a fish 
apparently mistaking the writhing red proboscis for a worm; as a consequence, the fish was harpooned in the mouth. Thus, bright coloration may be used to attract potential prey to striking distance. There are also observations suggesting that some species use venom components to attract their potential fish prey. In the field, certain species of fish have been seen swimming towards a Conus striatus [Poppe P., pers. commun.], consistent with the cone snail using a chemical attractant.

\section{Evolution}

Integrating Behavior, Phylogeny, Molecular Genetics and Neurobiology to Reconstruct Evolution

The ease in obtaining transcriptomic and genomic sequences has led to a substantial database of molecular genetic information for an ever-increasing number of $\mathrm{Co}$ nus species. This makes evolutionary reconstruction at a mechanistic level feasible. This will undoubtedly be a continuously changing story line, as more behavioral, neurobiological and molecular data are collected.

Diverse datasets are consistent with piscivorous Conus evolving from a worm-hunting ancestor. A specific evolutionary scenario supported by available molecular data is that there was a preadaptation in the vermivorous ancestor to fend off fish competitors for worm prey [Imperial et al., 2007; Olivera et al., 2014]. Several lines of evidence suggest that the ancestor that eventually gave rise to piscivory had evolved a venom component to elicit pain in fish competitors by increasing the activity of voltage-gated sodium channels in the appropriate sensory circuitry. This molecular weapon, called a $\delta$-conotoxin, is conserved among all fish-hunting species and is also found in several mollusk hunters and worm-hunting species (see online suppl. material, section II). It acts to keep sodium channels in an open state by inhibiting their inactivation [Terlau et al., 1996; Espiritu et al., 2001; Aman et al., 2015]. The $\delta$-conotoxin prepared these species for the jump to fish hunting.

It has been demonstrated that combining a $\delta$-conotoxin with a second toxin, a blocker of voltage-gated potassium channels, triggers a massive depolarization of axons in the nervous system of the envenomated animal, resulting in the rapid onset of a tetanic paralysis [Terlau et al., 1996]. This is postulated to be the key molecular innovation in the evolution of piscivory: once a potassium channel blocker was recruited, the ancestral worm-hunting snail would not only deter fish competitors, it would have an immobilized fish in front of it, a potential prey item.
Opportunistic feeding on such a fish could be the behavioral trait that potentially triggered the evolution of fishhunting cone snail lineages [Imperial et al., 2007; Olivera et al., 2014]. These initial events were presumably followed by additional adaptations that improved the efficacy of prey capture. Once the pharmacological combination to keep sodium channels open and simultaneously block (or inhibit) potassium channels had evolved, morphological adaptations such as developing a radular tooth bearing a strong backward-barbed accessory process that would physically tether the envenomated fish would clearly increase the probability of successful prey capture.

How did the more complex taser-and-tether prey-capture strategies arise? The phylogenetic tree suggests that from the ancestral state that caused a rapid immobilization, the evolution of effective motor cabal components would further increase the probability of prey capture by guarding against the prey escaping if it recovered prematurely from the electrically induced tetanus, and this was strongly selected for in several lineages. A different scenario likely explains evolution of the net-engulfment strategy. Nirvana cabal components would allow some early ancestral piscivorous forms to successfully capture multiple fish - this could be the origin of a divergent lineage leading to the net hunters. The adaptive ability to almost instantly immobilize a single prey would, in this lineage, become overshadowed by selection for increasing the number of prey captured in one foray. Once fish could be made disoriented and hypoglycemic by nirvana cabal toxins, instead of maximizing the probability of success in capturing a single fish, there could now be a different trajectory for selection: to capture as many fish as possible at one time.

There may be intermediate states that have components of the nirvana cabal, the lightning-strike cabal and the motor cabal in their venoms, possibly in some of the species in the Phasmoconus or Asprella clades. However, in the Gastridium clade (which may be a specialized offshoot of Phasmoconus, as suggested, though not strongly supported statistically by the phylogenetic tree shown in fig. 6), there could have been a bifurcation from an ancestral founder in two directions. In smaller species of the Gastridium clade, an effective tethering strategy evolved, and extant species like C. obscurus taser and tether their fish prey. In the evolution of larger extant species, however, selection apparently tilted towards capturing as many fish as possible, leading to the specialized adaptations found in C. geographus that enable the snail to potentially capture an entire school of fish using the net strategy. 
Interestingly, the molecular data strongly suggest that the events that initiated piscivory occurred more than once, a suggestion previously made in the literature [Duda et al., 2001; Espiritu et al., 2001; Duda and Palumbi, 2004]. On the basis of the phylogenetic tree shown in figure 6 , the most parsimonious scenario is that the transition from vermivory to piscivory happened twice. One event gave rise to Chelyconus, with a different set of events ultimately giving rise to the other seven clades of piscivorous cone snails found extant in the Indo-Pacific. The putative ancestral species are shown as two solid circles in the phylogenetic tree (fig. 6). The resulting piscivorous lineages display convergence at the behavioral level and in certain morphological adaptations (e.g. the presence of a strongly barbed accessory process in their radular teeth). Nevertheless, except for the $\delta$-conotoxins, which are conserved in the two lineages, strikingly divergent venom components are found that cause tetanic paralysis and neuromuscular block [Olivera et al., 2014]. The discovery that different toxin gene superfamilies have been employed for parallel neurobiological purposes (such as blocking voltage-gated potassium channels) in the Indo-Pacific and New World piscivorous lineages is consistent with the idea that the transition from vermivory to piscivory occurred independently in the ancestor of Chelyconus and again in the common ancestor of the other piscivorous lineages in the IndoPacific.

\section{Fish-Hunting Cone Snail Species That Also Hunt Other Prey}

If, as postulated in the preceding section, an intermediate state in the evolution of fish-hunting Conus species included both worm-hunting and opportunistic fish-eating behaviors, then we may expect to see generalist-type behavior in extant species. For two of the eight subgenera that we have discussed as primarily fish hunting (Pionoconus and Gastridium), the available evidence is consistent with all species in this subgenera being fish specialists; there is no documented evidence that these Conus species consume other prey. However, this is not the case for two other subgenera believed to be primarily fish hunting. Conus bullatus, the type species of the subgenus Textilia, has been reported to feed on mollusks as well as fish [McDowall, 1974, as cited by Röckel et al., 1995]. At least in aquaria, C. purpurascens will eat earthworms when presented as potential prey [Mari F., pers. commun.]. Conus ermineus can apparently attack other mollusks; an octopus beak was recovered in the gut of this species [Kohn, 2014].

Prey-Capture Strategies of Fish-Hunting Conus
Several Conus species that prey on fish belong to lineages that are primarily vermivorous. This was recently documented and described in detail for C. tessulatus [Aman et al., 2015]. C. tessulatus is a very efficient vermivore, but will attempt to envenomate fish opportunistically, albeit with very mixed success. These direct observations of attempts to envenomate fish are supported by the analysis of gut contents: both C. tessulatus and Conus eburneus, in the subgenus Tesseliconus, had fish bones in their guts and were previously reported to occasionally prey on fish [Kohn and Nybakken, 1975; Reichelt and Kohn, 1985]. In one specific instance, both fish bones and polychaete setae were found in the gut of a specimen of C. tessulatus [Kohn A., pers. commun.]. A specimen of Conus granulatus was reported to have regurgitated a puffer fish and a nereid polychaete after it was collected [Kohn, 2014]. Thus, there are scattered observations of some Conus species eating both fish and other prey from invertebrate phyla.

A unique example of a cone snail that preys on fish as well as other taxa is Californiconus californicus [Saunders and Wolfson, 1961; Kohn and Waters, 1966; Stewart and Gilly, 2005; Biggs et al., 2010]. This species has consistently been shown to be phylogenetically divergent from the majority of Conus species [Espiritu et al., 2001; Duda and Kohn, 2005] and has recently been assigned to a monospecific genus, Californiconus, based both on molecular data and anatomical criteria [Puillandre et al., 2014b]. When presented with a fish, individuals of C. californicus attempt to harpoon the fish, often succeeding even when the fish prey is larger than the cone snail. This species is the only cone snail observed to routinely hunt as a pack, whether the prey be a worm (their most frequently envenomated prey), another gastropod or even a shrimp [Biggs et al., 2010]. Among cone snails, this is a unique generalist carnivore.

\section{Perspectives}

Dietary shifts are central to the diversification of many animal groups including cone snails. Often they entail profound changes in many aspects of physiology, development and behavior. But seldom is it clear, from the evolved endpoints, how these changes were orchestrated and in particular how they were initiated. What were the events that set off cascades of reorganization, resulting in new ways of life embodied in groups of species that we now recognize as distinct clades and higher taxa? The fish-hunting cones appear to illustrate many of these 
steps, for example, through acts of opportunistic predation. In addition, their venom-based prey-capture techniques may allow what would otherwise be obscure portions of their ecological and developmental pathways of divergence to be reconstructed. By using behavioral observations in combination with molecular evolutionary, biochemical and pharmacological studies, information contained in present-day genome sequences can be exploited to more easily gain historical insights.

As was mentioned at the outset, cone snails are highly speciose, with much of their diversity only recently evolved. Thus ancestral character states can often be inferred, and there are often several independent derivations of a given syndrome, providing opportunities for comparisons that may support generalizations about the conditions that lead to certain kinds of specialization. A prime example is the lightning-strike cabal strategy to immobilize fish almost instantly into a rigid tetanic, paralytic state.

The discovery of 'weaponized insulin' also shows how combining evidence about physiology, behavior and the biochemistry of venom components may inform an evolutionary reconstruction. Evolving the ability to make fish hypoglycemic as a prey-capture strategy has certain strategic implications for prey capture. Somehow, the snail has to release the insulin before a fish becomes aware that the predator is present. Aquarium observations have shown how this is achieved by $C$. geographus, and pharmacological studies have revealed the other venom components which act together with the weaponized insulin to facilitate the capture of multiple fish. Recently, it has been shown that weaponized insulin is found in other lineages of fish-hunting cone snails [Safavi-Hemami et al., in preparation]. This discovery may ultimately provide insights into how these species have evolved their prey-capture strategies. Since the new evidence for weaponized insulin is for putative fish-hunting species that have never been directly observed, both the behavior and the broader physiological strategy are yet to be defined. The discovery of weaponized insulin in these species from other piscivorous lineages should provide more clear-cut insights into the evolution of the net-engulfment strategy of prey capture by fish-hunting snails.

There is persuasive evidence that venom components that prevent rapid inactivation of $\mathrm{Na}$ channels, the $\delta$-conotoxins, were an ancestral trait on the evolutionary road to specialist piscivores. The fact that all fish-hunting species studied so far, even opportunistic fish-hunting species such as $C$. tessulatus, have $\delta$-conotoxins as a venom component, strongly supports this venom component originating in worm-hunting ancestors. In contrast, the other essential venom component of the lightning-strike cabal, a toxin that blocks voltage-gated potassium channels, is lineage specific, with unrelated toxin gene families recruited for the same physiological function in each divergent lineage. Thus, the analysis of lightning-strike cabals in different lineages allowed a reconstruction of the evolution of the taser-and-tether strategy for capturing fish in different subgenera of $\mathrm{Co}$ nus.

Cones have attracted scientific interest because of their rapidly evolving genetically encoded toxins that appear to be fixed characteristics of any given individual and species. However, the effective deployment of those toxins appears to demand flexible and even intelligent behavior. Are cone snails smarter than their ancestors? If so, could this be one of the keys to their ecological and evolutionary success? Perhaps more attention should be paid to the strategic dimensions of their ways of life and to the possibility that behavior drives toxin evolution just as much as toxins drive behavior.

\section{Acknowledgments}

This work was supported by a program grant from the National Institute of General Medical Sciences (GM048677) and grant RFBR 14-04-31048 Mol-A of the Russian Foundation of Basic Research. We are grateful to Alan Kohn for sharing his field observations, and Jason Biggs and Dylan Taylor for supplying videos. Philippe Poppe and Frank Mari provided unique information

\footnotetext{
References Aman JW, Imperial J, Ueberheide BM, Zhang MM, Aguilar MB, Taylor D, Watkins M, Yoshikami D, Showers-Corneli P, Teichert W, Olivera BM (2015): Insights into the origins of fish hunting in venomous cone snails from studies on Conus tessulatus. Proc Natl Acad Sci USA 112:5087-5092.

Baldwin JM (1896): A new factor in evolution. Am Nat 30:441-451, 536-553.

-Biggs JS, Watkins M, Puillandre N, Ownby J-P, Lopez-Vera E, Christensen S, Moreno KJ, Bernaldez J, Navarro AL, Showers Corneli P, Olivera BM (2010): Evolution of Conus peptide toxins: analysis of Conus californicus Reeve, 1844. Mol Phylogenet Evol 56:1-12.

Chen L, Durr KL, Gouaux E (2014): X-ray structures of AMPA receptor-cone snail toxin complexes illuminate activation mechanism. Science 345:1021-1026.
}

72 
Conticello SG, Gilad Y, Avidan N, Ben-Asher E, Levy Z, Fainzilber M (2001): Mechanisms for evolving hypervariability: the case of conopeptides. Mol Biol Evol 18:120-131.

-Conticello SG, Pilpel Y, Glusman G, Fainzilber M (2000): Position-specific codon conservation in hypervariable gene families. Trends Genet 16:57-59.

-Craig AG, Bandyopadhyay P, Olivera BM (1999a): Post-translationally modified peptides from Conus venoms. Eur J Biochem 264:271-275.

-Craig AG, Norberg T, Griffin D, Hoeger C, Akhtar M, Schmidt K, Low W, Dykert J, Richelson E, Navarro V, Macella J, Watkins M, Hillyard D, Imperial J, Cruz LJ, Olivera BM (1999b): Contulakin-G, an O-glycosylated invertebrate neurotensin. J Biol Chem 274: 13752-13759.

Crispo E (2007): The Baldwin effect and genetic assimilation: revisiting two mechanisms of evolutionary change mediated by phenotypic plasticity. Evolution 61:2469-2479.

Crispo E (2008): Modifying effects of phenotypic plasticity on interactions among natural selection, adaptation and gene flow. J Evol Biol 21:1460-1469.

CCruz LJ, de Santos V, Zafaralla GC, Ramilo CA, Zeikus R, Gray WR, Olivera BM (1987): Invertebrate vasopressin/oxytocin homologs. Characterization of peptides from Conus geographus and Conus striatus venoms. J Biol Chem 262:15821-15824.

-Cruz LJ, Gray WR, Olivera BM, Zeikus RD, Kerr L, Yoshikami D, Moczydlowski E (1985): Conus geographus toxins that discriminate between neuronal and muscle sodium channels. J Biol Chem 260:9280-9288.

-Cruz LJ, Kupryszewski G, LeCheminant GW, Gray WR, Olivera BM, Rivier J (1989): $\mu$-Conotoxin GIIIA, a peptide ligand for muscle sodium channels: chemical synthesis, radiolabeling and receptor characterization. Biochemistry 28:3437-3442.

-Donevan SD, McCabe RT (2000): Conantokin-G is an NR2B-selective competitive antagonist of N-methyl-D-aspartate receptors. Mol Pharmacol 58:614-623.

Duda TF Jr, Kohn AJ (2005): Species-level phylogeography and evolutionary history of the hyperdiverse marine gastropod genus Conus. Mol Phylogenet Evol 34:257-272.

Duda TF Jr, Kohn AJ, Palumbi SR (2001): Origins of diverse feeding ecologies within Conus, a genus of venomous marine gastropods. Biol J Linn Soc 73:391-409.

Duda TF Jr, Palumbi SR (1999): Molecular genetics of ecological diversification: duplication and rapid evolution of toxin genes of the venomous gastropod Conus. Proc Natl Acad Sci USA 96:6820-6823.

D Duda TE Jr, Palumbi SR (2004): Gene expression and feeding ecology: evolution of piscivory in the venomous gastropod genus Conus. Proc Soc Biol 271:1165-1174.

England LJ, Imperial J, Jacobsen R, Craig AG, Gulyas J, Akhtar M, Rivier J, Julius D, Olivera BM (1998): Inactivation of a serotonin-gated ion channel by a polypeptide toxin from marine snails. Science 281:575-578.

Espiritu DJ, Watkins M, Dia-Monje V, Cartier E, Cruz LJ, Olivera BM (2001): Venomous cone snails: molecular phylogeny and the generation of toxin diversity. Toxicon 39:18991916.

- Feldman D, Olivera BM, Yoshikami D (1987): Omega Conus geographus toxin: a peptide that blocks calcium channels. FEBS Lett 214: 295-300.

Gowd KH, Han TS, Twede VD, Gajewiak J, Smith MD, Watkins M, Platt RJ, Toledo G, White HS, Olivera BM, Bulaj G (2012): Conantokins derived from the Asprella clade impart conRl$\mathrm{B}$, an N-methyl D-aspartate receptor antagonist with a unique selectivity profile for NR2B subunits. Biochemistry 51:4685-4692.

-Gowd KH, Watkins M, Twede VD, Bulaj G, Olivera BM (2010): Characterization of conantokin Rl-A: molecular phylogeny as structure/ function study. J Pept Sci 16:375-382.

- Gray WR, Luque A, Olivera BM, Barrett J, Cruz LJ (1981): Peptide toxins from Conus geographus venom. J Biol Chem 256:4734-4740.

- Haack JA, Rivier J, Parks TN, Mena EE, Cruz LJ, Olivera BM (1990): Conantokin T: a $\gamma$-carboxyglutamate-containing peptide with $\mathrm{N}$ methyl-D-aspartate antagonist activity. J Biol Chem 265:6025-6029.

Hu H, Bandyopadhyay PK, Olivera BM, Yandell M (2012): Elucidation of the molecular envenomation strategy of the cone snail Conus geographus through transcriptome sequencing of its venom duct. BMC Genomics 13:284.

Imperial J, Silverton N, Olivera BM, Bandyopadhyay P, Sporning A, Ferber M, Terlau H (2007): Using chemistry to reconstruct evolution: on the origins of fish-hunting in venomous cone snails. Proc Am Phil Soc 151:185-200.

Kohn AJ (1956): Piscivorous gastropods of the genus Conus. Proc Natl Acad Sci USA 42:168171.

Kohn AJ (2014): Conus of the Southeastern United States and Caribbean. Princeton, Princeton University Press.

Kohn AJ, Nybakken JW (1975): Ecology of Conus on eastern Indian Ocean fringing reefs: diversity of species and resource utilization. Mar Biol 29:211-234.

Kohn AJ, Waters V (1966): Escape responses of three herbivorous gastropods to the predatory gastropod Conus textile. Anim Behav 14: 340-345.

-Lee HK, Zhang L, Smith MD, Walewska A, Vellore NA, Baron R, McIntosh JM, White HS, Olivera BM, Bulaj G (2015): A marine analgesic peptide, contulakin- $G$, and neurotensin are distinct agonists for neurotensin receptors: uncovering structural determinants of desensitization properties. Front Pharmacol 6:11.

McDowall J (1974): Cone predation. Hawaiian Shell News 22:3.

McIntosh JM, Olivera BM, Cruz LJ, Gray WR (1984): $\gamma$-Carboxyglutamate in a neuroactive toxin. J Biol Chem 259:14343-14346.
McManus OB, Musick JR (1985): Postsynaptic block of frog neuromuscular transmission by conotoxin GI. J Neurosci 5:110-116.

- Mena EE, Gullak MF, Pagnozzi MJ, Richter KE, Rivier J, Cruz LJ, Olivera BM (1990): Conantokin-G: a novel peptide antagonist to the $\mathrm{N}$ methyl-D-aspartate acid (NMDA) receptor. Neurosci Lett 118:241-244.

Olivera BM (1997): E.E. Just Lecture, 1996. Conus venom peptides, receptor and ion channel targets, and drug design: 50 million years of neuropharmacology. Mol Biol Cell 8:21012109.

Olivera BM (2002): Conus venom peptides: reflections from the biology of clades and species. Annu Rev Ecol Evol Syst 33:25-42.

Olivera BM, Cruz LJ (2001): Conotoxins, in retrospect. Toxicon 39:7-14.

-Olivera BM, Gray WR, Zeikus R, McIntosh JM, Varga J, Rivier J, de Santos V, Cruz LJ (1985): Peptide neurotoxins from fish-hunting cone snails. Science 230:1338-1343.

-Olivera BM, McIntosh JM, Cruz LJ, Luque FA, Gray WR (1984): Purification and sequence of a presynaptic peptide toxin from Conus geographus venom. Biochemistry 23:50875090.

Olivera BM, Rivier J, Clark C, Ramilo CA, Corpuz GP, Abogadie FC, Mena EE, Woodward SR, Hillyard DR, Cruz LJ (1990): Diversity of Conus neuropeptides. Science 249:257-263.

-Olivera BM, Showers Corneli P, Watkins M, Fedosov A (2014): Biodiversity of cone snails and other venomous marine gastropods: evolutionary success through neuropharmacology. Annu Rev Anim Biosci 2:487513.

Olivera BM, Walker C, Cartier GE, Hooper D, Santos AD, Schoenfeld R, Shetty R, Watkins M, Bandyopadhyay P, Hillyard DR (1999): Speciation of cone snails and interspecific hyperdivergence of their venom peptides. Potential evolutionary significance of introns. Ann NY Acad Sci 870:223-237.

Puillandre N, Bouchet P, Duda TF Jr, Kauferstein S, Kohn AJ, Olivera BM, Watkins M, Meyer C (2014a): Molecular phylogeny and evolution of the cone snails (Gastropoda, Conoidea). Mol Phylogenet Evol 78:290-303.

- Puillandre N, Duda TF Jr, Meyer CP, Olivera BM, Bouchet P (2014b): One, four or 100 genera? A new classification of the cone snails. J Mollus Stud 81:1-23.

Reichelt RE, Kohn AJ (1985): Feeding and distribution of predatory gastropods on some Great Barrier Reef platforms. Proc Fifth Int Coral Reef Congress, Tahiti, pp 191-196.

Röckel D, Korn W, Kohn AJ (1995): Manual of the Living Conidae. Wiesbaden, Hemmen.

Safavi-Hemami H, Gajewiak J, Karanth S, Robinson SD, Ueberheide B, Douglass AD, Schlegel A, Imperial JS, Watkins M, Bandyopadhyay PK, Yandell M, Li Q, Purcell AW, Norton RS, Ellgaard L, Olivera BM (2015): Specialized insulin is used for chemical warfare by fishhunting cone snails. Proc Natl Acad Sci USA 112:1743-1748. 
Safavi-Hemami H, Hu H, Gorasia DG, Bandyopadhyay PK, Veith PD, Young ND, Reynolds EC, Yandell M, Olivera BM, Purcell AW (2014): Combined proteomic and transcriptomic interrogation of the venom gland of $\mathrm{Co}$ nus geographus uncovers novel components and functional compartmentalization. Mol Cell Proteomics 13:938-953.

-Salisbury SM, Martin GG, Kier WM, Schulz JR (2010): Venom kinematics during prey capture in Conus: the biomechanics of a rapid injection system. J Exp Biol 213:673-682.

-Santos AD, McIntosh JM, Hillyard DR, Cruz LJ, Olivera BM (2004): The A-superfamily of conotoxins: structural and functional divergence. J Biol Chem 279:17596-17606.

Saunders PR, Wolfson F (1961): Food and feeding behavior in Conus californicus Hinds 1844. Veliger 3:73-76.
Schulz JR, Norton AG, Gilly WF (2004): The projectile tooth of a fish-hunting cone snail: $\mathrm{Co}$ nus catus injects venom into fish prey using a high-speed ballistic mechanism. Biol Bull 207: 77-79.

Stewart J, Gilly WF (2005): Piscivorous behavior of a temperate cone snail, Conus californicus. Biol Bull 209:146-153.

Teichert RW, Olivera BM, McIntosh JM, Bulaj G, Horvath MP (2015): The molecular diversity of conoidean venom peptides and their targets: from basic research to therapeutic applications; in King GF (ed): Venoms to Drugs: Venom as a Source for the Development of Human Therapeutics. London, Royal Society of Chemistry, pp 163-203.

Terlau H, Olivera BM (2004): Conus venoms: a rich source of novel ion channel-targeted peptides. Physiol Rev 84:41-68.

- Terlau H, Shon K, Grilley M, Stocker M, Stühmer W, Olivera BM (1996): Strategy for rapid immobilization of prey by a fish-hunting cone snail. Nature 381:148-151.
Tucker JK, Tenorio MJ (2009): Systematic Classification of Recent and Fossil Conoidean Gastropods. Hackenheim, ConchBooks.

Twede VD, Teichert RW, Walker CS, Gruszczynski P, Kazmierkiewicz R, Bulaj G, Olivera BM (2009): Conantokin-Br from Conus brettinghami and selectivity determinants for the NR2D subunit of the NMDA receptor. Biochemistry 48:4063-4073.

Woodward SR, Cruz LJ, Olivera BM, Hillyard DR (1990): Constant and hypervariable regions in conotoxin propeptides. EMBO J 9:10151020.

Yarotskyy V, Elmslie KS (2010): Interference between two modulators of N-type ( $\left.\mathrm{Ca}_{\mathrm{v}} 2.2\right) \mathrm{cal}-$ cium channel gating demonstrates that omega-conotoxin GVIA disrupts open state gating. Biochim Biophys Acta 1798:1821-1828. 